Microstructure and Mechanical Instability of Water-Quenched U-6wt\% Nb Alloy Affected by Long-Term Aging

Luke Hsiung, Jikou Zhou

December 7, 2005 
This document was prepared as an account of work sponsored by an agency of the United States Government. Neither the United States Government nor the University of California nor any of their employees, makes any warranty, express or implied, or assumes any legal liability or responsibility for the accuracy, completeness, or usefulness of any information, apparatus, product, or process disclosed, or represents that its use would not infringe privately owned rights. Reference herein to any specific commercial product, process, or service by trade name, trademark, manufacturer, or otherwise, does not necessarily constitute or imply its endorsement, recommendation, or favoring by the United States Government or the University of California. The views and opinions of authors expressed herein do not necessarily state or reflect those of the United States Government or the University of California, and shall not be used for advertising or product endorsement purposes.

This work was performed under the auspices of the U.S. Department of Energy by University of California, Lawrence Livermore National Laboratory under Contract W-7405-Eng-48. 


\section{Microstructure and Mechanical Instability of Water-Quenched U-6wt\% Nb Alloy Affected by Long-Term Aging}

Luke Hsiung and Jikou Zhou

Materials Science and Technology Division, L-352

\section{Objectives and accomplishments}

A combinative approach of microhardness testing, tensile testing, and TEM microstructural analysis was employed to study the microstructure and mechanical instability of a waterquenched U-6wt.\% Nb (WQ-U6Nb) alloy subjected to different aging schedules including artificial aging at $200^{\circ} \mathrm{C}$, 15-year natural aging at ambient temperatures, and 15-year natural aging followed by accelerative aging at $200^{\circ} \mathrm{C}$. The changes in mechanical property during and after the aging processes were examined using microhardness and tensile-testing methods. During the early stages of artificial aging at $200^{\circ} \mathrm{C}$, the microhardness of WQ-U6Nb alloy increased, i.e., age hardening, as a result of the development of nanoscale modulation caused by spinodal decomposition. Coarsening of the modulated structure occurred after a prolonged aging at $200^{\circ} \mathrm{C}$ for 16 hours, and it led to a decrease of microhardness, i.e., age softening. Phase instability was also found to occur in WQ-U6Nb alloy that was subjected to a 15-year natural aging at ambient temperatures. The formation of partially ordered domains resulting from a spinodal modulation with an atomic-scale wavelength rendered the appearance of swirl-shape antiphase domain boundaries (APBs) observed in TEM images. Although it did not cause a significant change in microhardness, 15-year natural aging has dramatically affected the aging mechanisms of the alloy isothermally aged at $200^{\circ} \mathrm{C}$. Microhardness values of the NA alloy continuously increased and no age softening was found after isothermal aging at $200^{\circ} \mathrm{C}$ for 96 hours as a result of the phase decomposition of partially ordered domains into Nb-depleted $\alpha$ phase and $\mathrm{Nb}$-enriched $\mathrm{U}_{3} \mathrm{Nb}$ ordered phase in the alloy. It is concluded that the long-term natural aging changes the transformation pathway of WQ-U6Nb, and it leads to order-disorder transformation, precipitation hardening, and ductility embrittlement of WQ-U6Nb alloy.

\section{$\underline{\text { Introduction }}$}

U-6wt.\% $\mathrm{Nb}$ (U6Nb) alloy contains approximately 14 atomic percent of niobium that is close to the monotectoid composition (13.3 at.\% Nb). At high temperatures above $647^{\circ} \mathrm{C}$, the equilibrium phase is a bcc $(\gamma)$ phase. A water-quenched U-6 wt.\% Nb (WQ-U6Nb) from $\gamma$ (bcc)field solid solution has a microstructure containing martensitic phases that are supersaturated with $\mathrm{Nb}$. In the stresses-induced martensitic transformation, a variant of the low-temperature orthorhombic $(\alpha)$ phase is usually formed. This phase is designated $\alpha^{\prime}$ martensite since its lattice parameters differ from the equilibrium $\alpha$ phase. Two additional variant phases, a monoclinic distortion of $\alpha^{\prime}$, named $\alpha^{\prime \prime}$ martensite, or a tetragonal distortion of $\gamma$, named $\gamma^{0}$ martensite, may also be formed within the water-quenched alloy. All these variant phases are Nb supersaturated. These are shown in the phase diagram in Figure 1 [1]. The WQ-U6Nb alloy has improved mechanical properties (ductility and toughness) [2,3] and excellent corrosion resistance [4,5] because of the uniform distribution of niobium atoms in the solid solution that suppresses the diffusional decomposition reaction to form a two-phase (a Nb-depleted $\alpha$ phase and a Nbenriched $\gamma$ phase) cellular microstructure. It has also been demonstrated that the water-quenched WQ-U6Nb alloy containing $\alpha^{\prime \prime}$ martensite reveals shape memory effect $[6,7]$. 
Artificial aging of the $\alpha^{\prime \prime}$ martensite in a temperature ranging from $250^{\circ} \mathrm{C}$ to $400^{\circ} \mathrm{C}$ results in an increase of yield strength [2,3,8,9]. Using Atom Probe Field Ion Microscopy (APFIM) method, Beverini and Edmonds [3] found an age hardening/softening phenomenon associated with nanometer length-scale of segregation reaction. The nanoscale segregation may result from spinodal decomposition [10]. Spinodal decomposition is a continuous clustering mechanism in which the supersaturated solid solution separates spontaneously into solute-lean and solute-rich phases within the parent phase domain through uphill diffusion [11]. It is a common phase transient mechanism leading to aging hardening and subsequent softening when the structure is coarsened. However, the spinodal decomposition has never been directly observed or confirmed in this alloy.

The mechanical parts made of WQ-U6Nb alloy have been in service for more than a decade. The major issues and concerns with these parts are how the microstructure and mechanical properties have changed so far, and how will these changes proceed in the future. In order to address these issues, we need to know how the microstructure has been evolved since the alloy was put into service at ambient temperatures. We also need to know how the microstructural changes over the past decades have affected the subsequent microstructure and mechanical stability in the future. In this study, we first investigated the aging behavior of WQ-U6Nb that was artificially aged at $200^{\circ} \mathrm{C}$. We then examined the microstructure of WQ-U6Nb in service at ambient temperatures, which is equivalent to natural aging (NA), for 15 years. The NA alloy was then subjected to artificial aging at $200^{\circ} \mathrm{C}$ to study the changes of mechanical property as well as the aging mechanisms. The changes of mechanical strength were subsequently examined using microhardness testing and tensile testing methods.

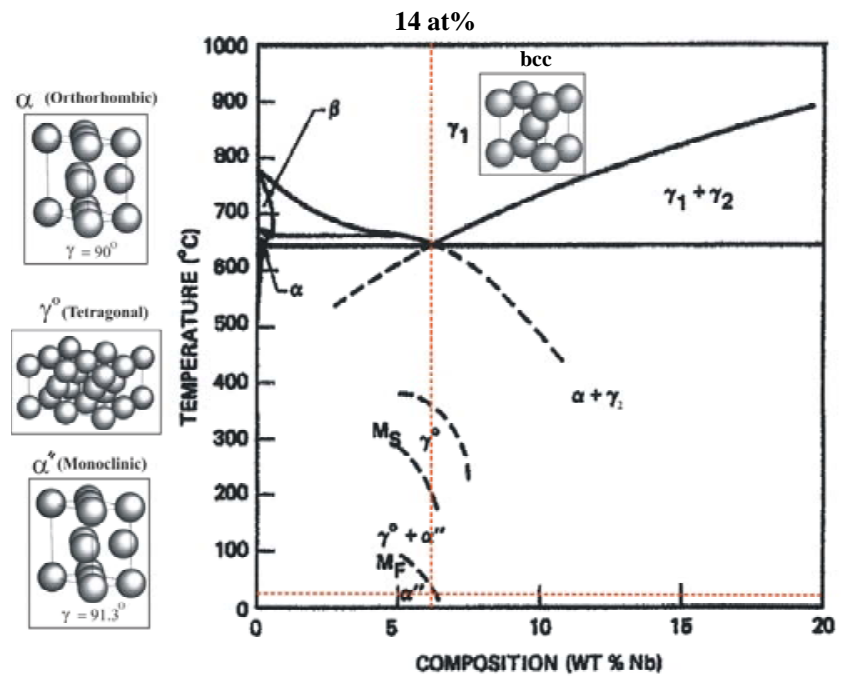

Figure 1: U-Nb phase diagram and the crystal structure units relevant to the microstructures that were observed in this study.

\section{$\underline{\text { Approach }}$}

The U6Nb alloy used for this investigation was wrought processed from Rocky Flats VAR ingot at the BWXT/Bechtel Y-12 plant. Detailed information regarding the fabrication process can be found in Ref. [2]. The naturally aged specimens were machined directly from a $38 \mathrm{~mm}$ thick plate. Rod-shaped specimens of $3 \mathrm{~mm}$ in diameter were prepared for microstructure 2 
analysis and accelerative aging. The water-quenched U6Nb alloy was obtained by solution treating the alloy at $800^{\circ} \mathrm{C}$ for 4 hours followed by water quenching. It was then followed by artificially aging. Both accelerative aging and artificial aging were carried out in a vacuum furnace at $200^{\circ} \mathrm{C}$. The naturally aged (NA) samples used for this investigation were prepared from a 15-year old mechanical part. Microhardness measurements were performed on all these samples using a Vickers-hardness indenter. This was done to monitor the mechanical property change during aging processes. The applied load was $50 \mathrm{~g}$ and the time duration is 35 seconds for each test. To obtain a statistically significant value, more than six tests were conducted for each measurement. The microstructures of the alloy in as water-quenched (WQ), WQ plus artificial age (AA), WQ plus natural age (NA), and WQ plus NA and AA conditions were examined using a JEOL-200CX transmission electron microscope (TEM). TEM foils were machined from the rod-shape samples, and the finial thinning of the foils was prepared by twinjet electropolishing in a solution of 45 vol\% methanol, 45 vol\% butyl alcohol, and 10 vol\% nitric acid at $50 \mathrm{~V}$ and $-20^{\circ} \mathrm{C}$.

\section{$\underline{\text { Results }}$}

\section{Artificial aging of WQ alloy at $200{ }^{\circ} \mathrm{C}$}

The changing of microhardness of WQ-U6Nb with increasing time of artificial aging at $200^{\circ} \mathrm{C}$ is presented in Figure 2. The microhardness obtained from a water-quenched specimen is also shown in Figure 2 for a comparison. The alloy in water-quenched condition had an average microhardness of 190.0. It rapidly increased to 210.0 after aging for 2 hours. The microhardness values increased to 237.0 for 4 hours and 254.8 for 8 hours. Within the first 8 hours of aging, the strengthening continued but with a decreasing trend. Further aging caused softening after the microhardness reaches a maximum value at 8 hours, and the microhardness reduced to 237 at 16 hours (Figure 2). No significant change on TEM morphology was found in the lowmagnification images shown in Figure 3. However, modulated microstructures were observed at in high-magnification images shown in Figure 4. The modulated structure contains very fine domains with thickness of $\sim 3 \mathrm{~nm}$, which was attributed to the formation of Nb-lean and Nb-rich phases. The modulated structure was found to initiate at 2 hours, and fully developed between 4 hours and 8 hours. The modulated structure resulted in the formation of satellite spots around the Bragg diffraction spots of the diffraction pattern. These are indicated in the diffraction patterns shown in Figure 4. It is worth noting that the dark/bright fringes in TEM image accompanied by the appearance of satellite diffraction spots are typically resulting from spinodal decomposition [10, 12]. For an artificial aging at $200^{\circ} \mathrm{C}$, spinodal decomposition initiated and grew within the first 8 hours. After modulation was fully developed, further aging led to the coarsening of the modulated structure. The modulation wavelength increased to $\sim 50 \mathrm{~nm}$ after aging for 16 hours, which is shown in Figure 5. The microhardness is significantly decreased (Figure 2) when the coarsening of modulation occurred. 


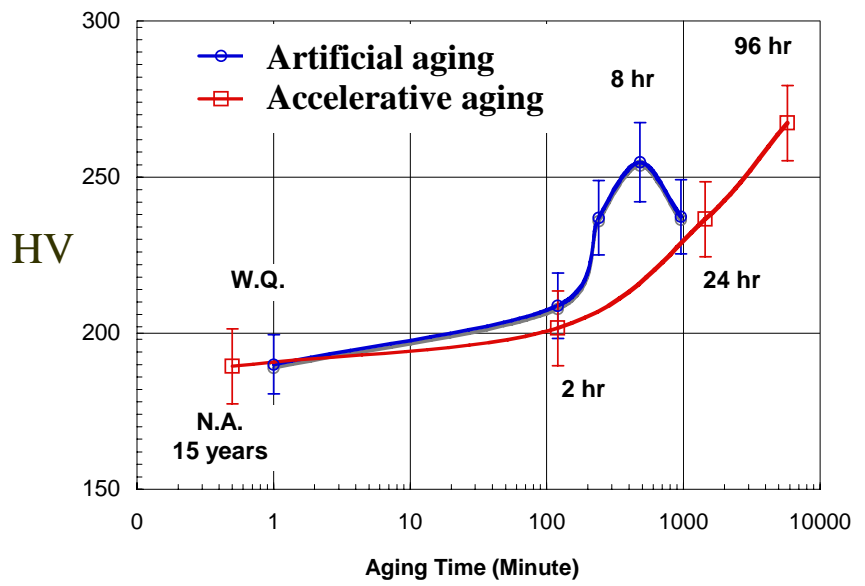

Figure 2: Changes of microhardness during the artificial aging of WQ-U6Nb alloy and the accelerative aging of 15-year NA-U6Nb alloy.
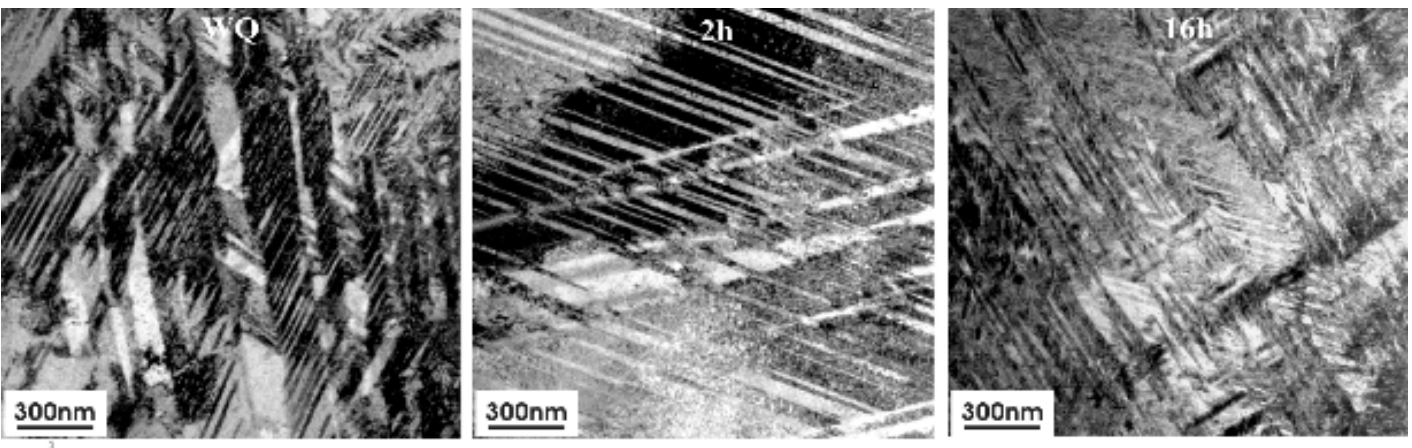

Figure 3: Microstructures of WQ-N6Nb before and during artificial aging at $200{ }^{\circ} \mathrm{C}$. There was no observable change in these TEM images of low magnifications.
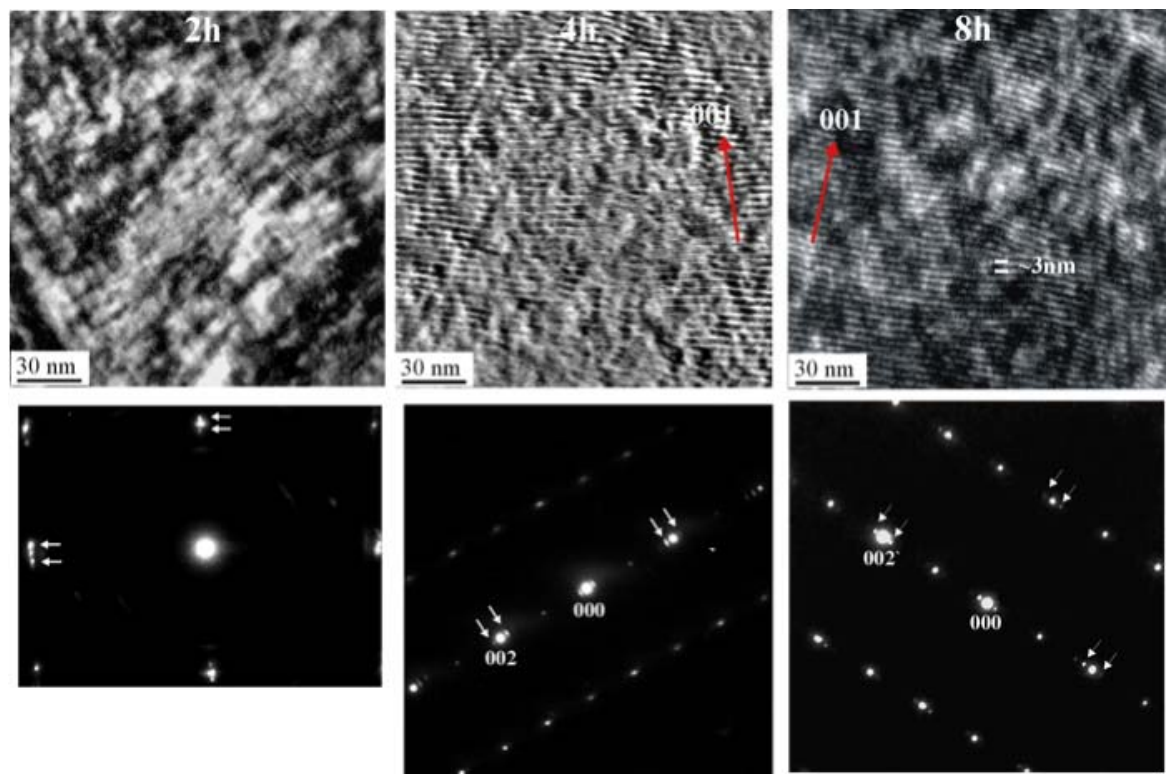

Figure 4: Development of composition modulation in the alloy during artificial aging at $200{ }^{\circ} \mathrm{C}$. 


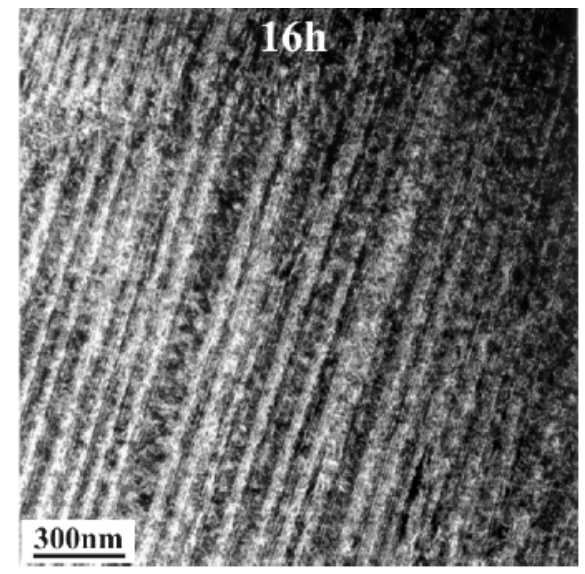

Figure 5: Coarsening of the composition modulation after artificially aged for 16 hours.

\section{Natural aging of WQ alloy at ambient temperatures}

An important change of the microstructure in the 15-year NA sample has been verified using bright-field and dark-field TEM imaging techniques. The observation and contrast analysis of swirl-shaped antiphase domain boundaries (APBs) are demonstrated in Figure 6. The contrast of antiphase domain boundary (also known as $\pi$ boundary) is visible when the phase angle $\alpha=$ $2 \pi \mathbf{g} \cdot \mathbf{P}=\pi$ and is invisible when $\alpha=2 \pi$ (where $\mathbf{g}$ is the reflection vector for imaging, and $\mathbf{P}$ is the displacement vector of APB) [12]. The bright-field image in Figure 6a clearly displays the swirlshape feature of APBs. These APBs are visible in the dark-field images that were obtained using $00 \overline{1}$ (Figure 6b) and $0 \overline{2} \overline{1}$ (Figure 6c) superlattice reflections. However, the APBs become invisible in Figure 6d which was obtained using a $0 \overline{2} 0$ fundamental reflection. The formation of APBs reveals the occurrence of a disorder-order transformation, which can be attributed to the formation of chemically ordered domains within the NA sample. In essence, the ordered phase domain had the same crystal structure as that of the disordered phase domain, except it took up a superlattice arrangement because of the periodic occupation of lattice sites by specific atom species.

(a)

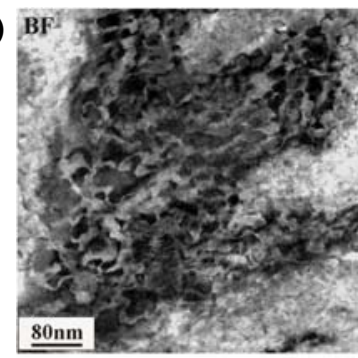

(b)

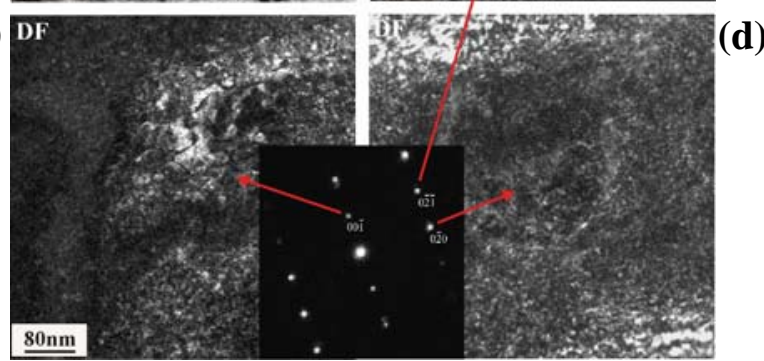

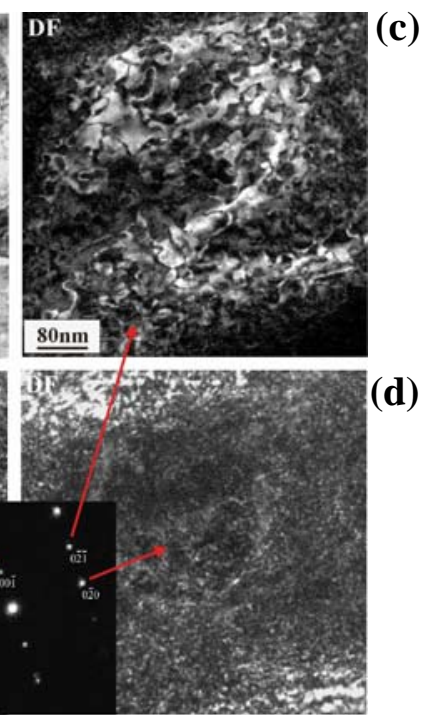

(c)

Figure 6: Bright-field and dark-field TEM images of swirl-shaped APBs observed in the same area of 15-year NA sample. The APBs are visible when using $00 \overline{1}$ and $0 \overline{2} \overline{1}$ superlattice reflections to image but become invisible when using $0 \overline{2} 0$ fundamental reflection to image. 
Based on the above TEM observations, a new chemically ordered $\alpha^{\prime \prime}$ phase is proposed and its structure is identified by a comparison between observed and simulated diffraction patterns. The illustrations of two possible schemes for the disorder-order transformation in $\alpha^{\prime \prime}$ phase are presented in Figure 7. For the ordering transformation of Scheme I (Figure 7a), U atoms occupy the following three specific lattice sites of the ordered superlattice (4 lattice sites/unit cell): $(0,5 / 6,1 / 2),(1 / 2,1 / 3,1 / 2)$, and $(1 / 2,1 / 2,0)$, whereas the $(0,0,0)$ lattice site is randomly occupied by $\mathrm{U}$ and $\mathrm{Nb}$ atoms, in which the probability of the site occupied by $\mathrm{U}$ and $\mathrm{Nb}$ are $44 \%$ and $56 \%$, respectively. For the ordering transformation of Scheme II (Figure 7b), U atoms occupy $(0,5 / 6,1 / 2)$ and $(1 / 2,1 / 3,1 / 2)$ lattice sites, whereas the $(0,0,0)$ and $(1 / 2,1 / 2,0)$ lattice sites are randomly occupied by $\mathrm{U}$ and $\mathrm{Nb}$ atoms, in which the probability of the sites occupied by $\mathrm{U}$ and $\mathrm{Nb}$ are $72 \%$ and $28 \%$, respectively. The systematic variations in the atomic positions result in different ordered-domains separated by APBs across which the atoms have the wrong immediate neighbors, which is illustrated in Figure 7(c).

(a)

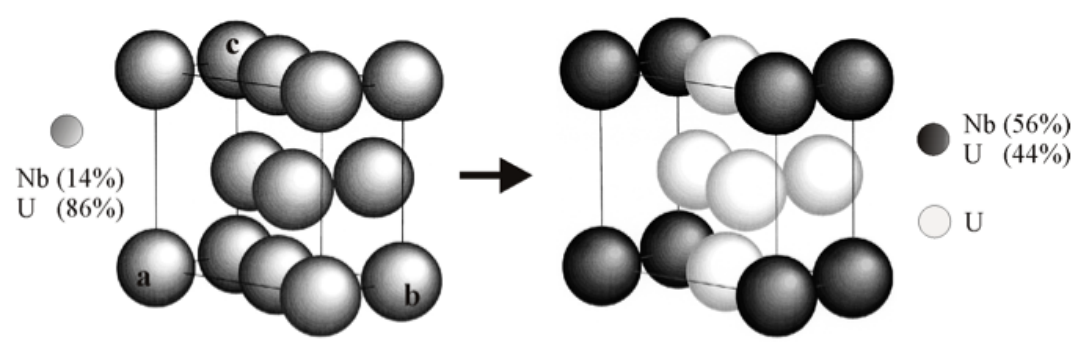

(b)
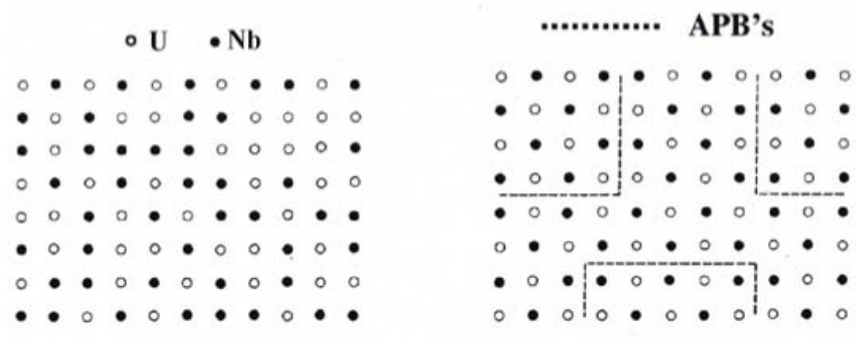

(c)
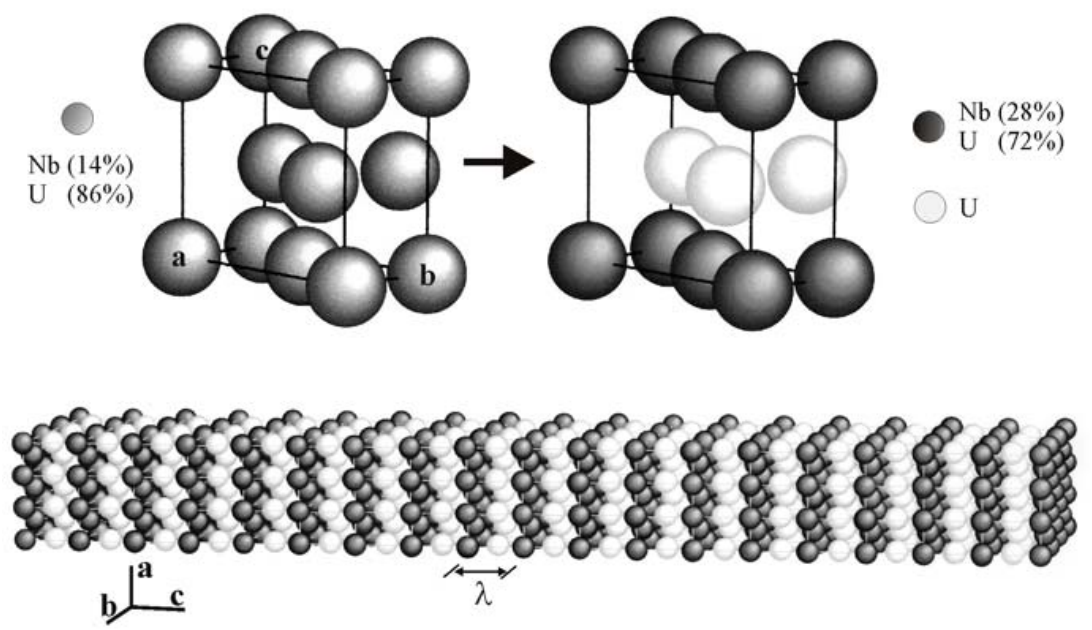

Figure 7: Two ordering schemes that may result in the formation of the swirl-shaped APB structure. (a) Scheme I; (b) Scheme II; and (c) Schematic illustration of the formation of APB structure in 2 dimensions.

The [110]-, [310]-, [312]-, and [100]-zone selected-area diffraction patterns generated from the 15 -year NA sample are shown in Figure 8. The corresponding zone diffraction patterns 6 
simulated according to the Schemes I and II ordering transformations are also displayed. It is noted that the simulation patterns of the [110]-, [310]-, and [312]-zone are identical between Scheme I and II as shown in Figure 8a. The simulation patterns of the [001]-zone are different between Scheme I and II (Figure 8b). The ordering transformation of $\alpha^{\prime \prime}$ phase is identified to be most likely of Scheme II type in accordance to the observed and simulated [100]-zone patterns as shown in Figure 8b.

(a)

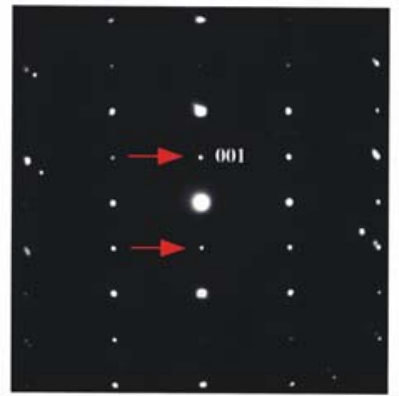

[110]

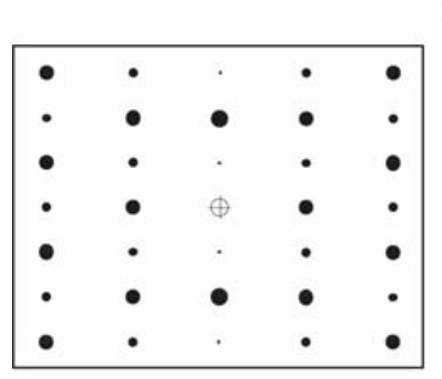

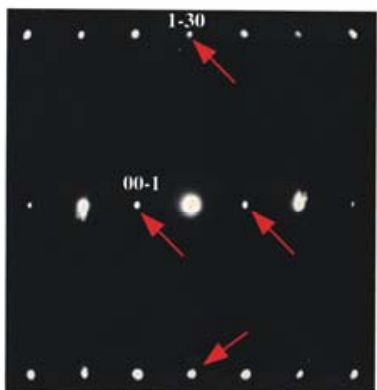

[310]

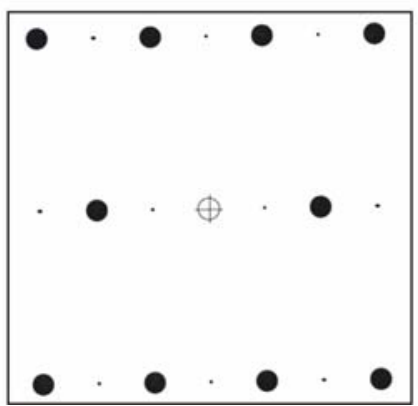

(b)

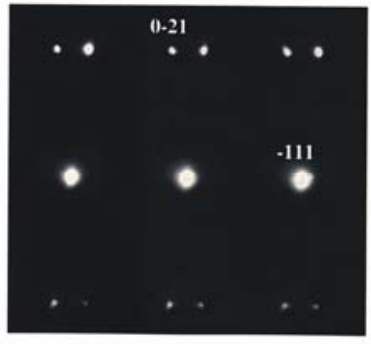

[312]

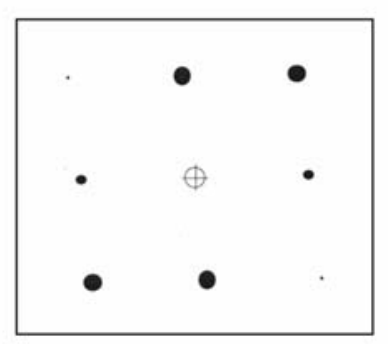

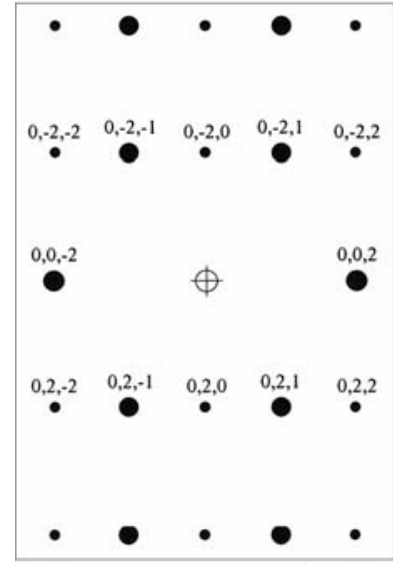

Disordered $\alpha^{\prime \prime}$

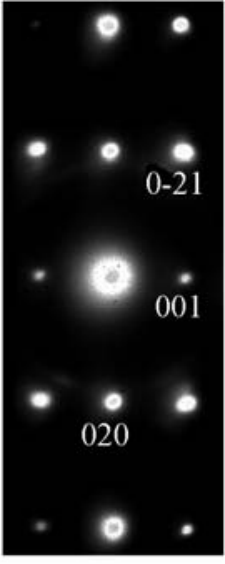

[100]

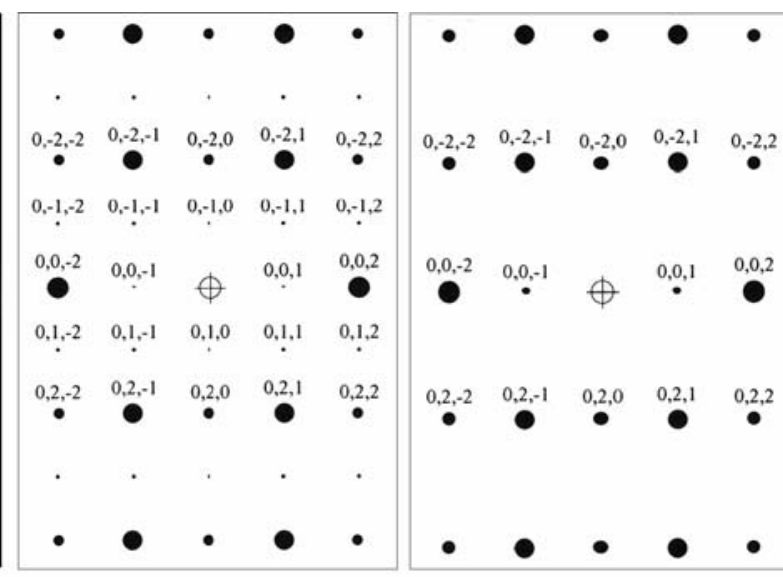

Scheme I
Scheme II

Figure 8: Identification of the crystallographic structure of the partially ordered phase presented in the swirl-shaped APB feature. (a) The two proposed structures have the same SAED patterns of [110]-, [310]-, and [312]-zone. (b) The two structures have different SAD of [100] zone.

\section{Accelerative aging of NA alloy at $200^{\circ} \mathrm{C}$}

In an effort to study how the long-term natural aging affects the subsequent aging kinetics of 7 
the alloy, a 15-year NA alloy sample was isothermally aged at $200^{\circ} \mathrm{C}$. The changes of microhardness with increasing aging durations are plotted in Figure 2. Notice that the 15-year NA sample has an average microhardness value of 189.4, which is very close to that of as waterquenched U6Nb alloy. This suggests that natural aging over the past 15 years does not cause a significant change in mechanical property of the alloy. The microhardness of the alloy slightly increases to 202.6 after aging for 2 hours, and it continuously increases to 236.5 and 267.3 after aging for 24 hours and 96 hours, respectively. It is interesting to note that the NA alloy was not age softened even after it aging for 96 hours, and this is very different from the artificial aging of as water-quenched $\mathrm{U} 6 \mathrm{Nb}$, in which age softening occurred after aging at $200^{\circ} \mathrm{C}$ for longer than 8 hours.

A typical microstructure of NA alloy isothermally aged at $200^{\circ} \mathrm{C}$ for 96 hours is shown in Figure 9. Again, there is no significant change observed at low magnifications. Also, there is no modulated structure similar to that shown in Figure 4 was observed at high magnifications. However, the appearance of superlattice diffraction spots in electron diffraction patterns revealed that ordered $\alpha$ " phase was formed after the NA alloy was isothermally aged for 96 hours at $200^{\circ} \mathrm{C}$. Typical selected-area electron diffraction (SAD) patterns of [010]-, [001]-, and [110]zone are presented in Figures $9 \mathrm{a}-9 \mathrm{~d}$. The SAD patterns show readily that a fully ordered $\mathrm{U}_{3} \mathrm{Nb}$ phase was formed. It is noted that the two phases identified by comparing the SAD patterns with the simulated diffraction patterns are $\alpha$ and $\mathrm{U}_{3} \mathrm{Nb}$ phases. The simulated SAD patterns of [010] zone axis are presented in Figure 9. We did not observe the diffraction pattern corresponding to $\mathrm{UNb}$ with 50 at.\% of Nb, which was observed in the NA specimens (Figures 6-8).

(a)
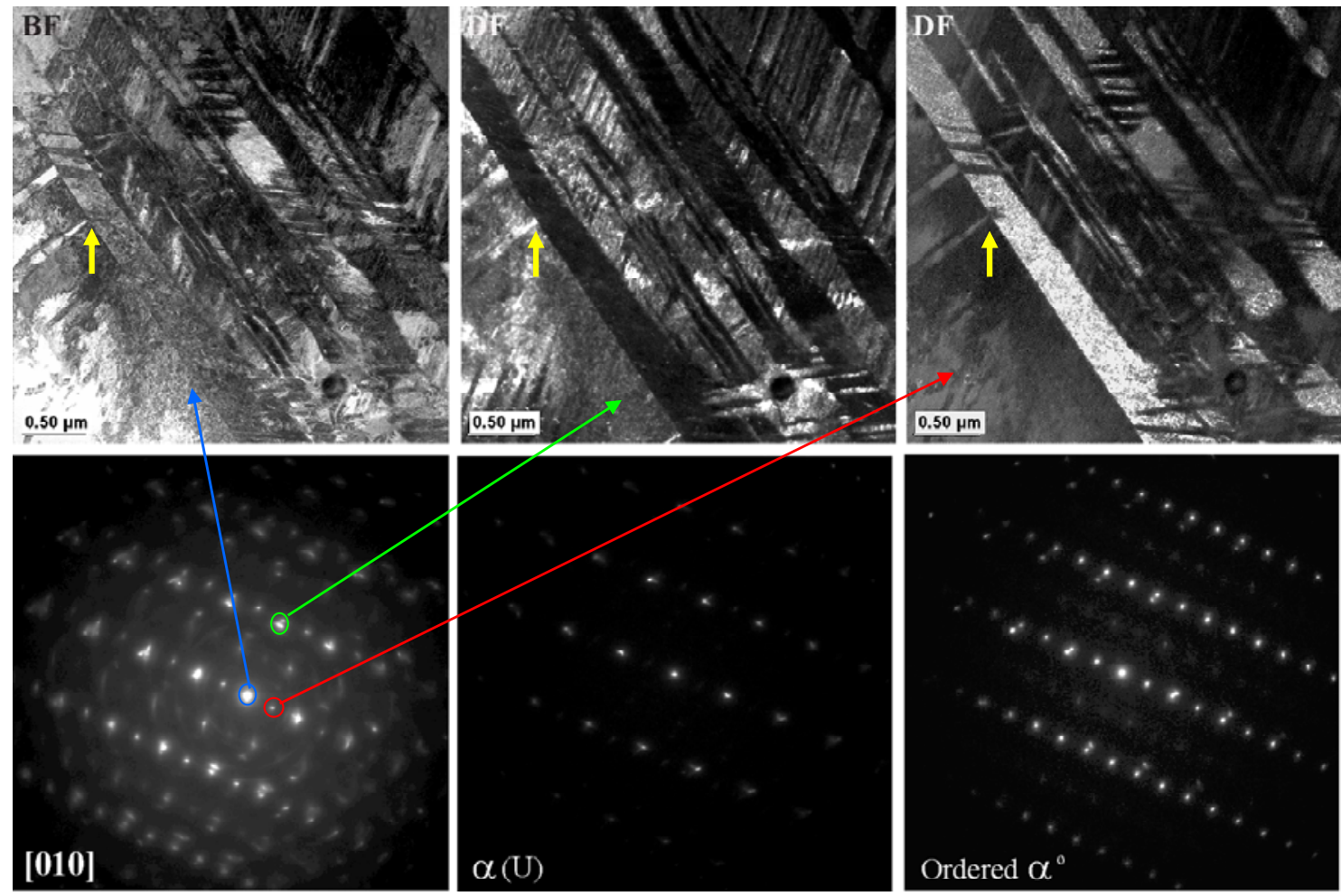
(b)

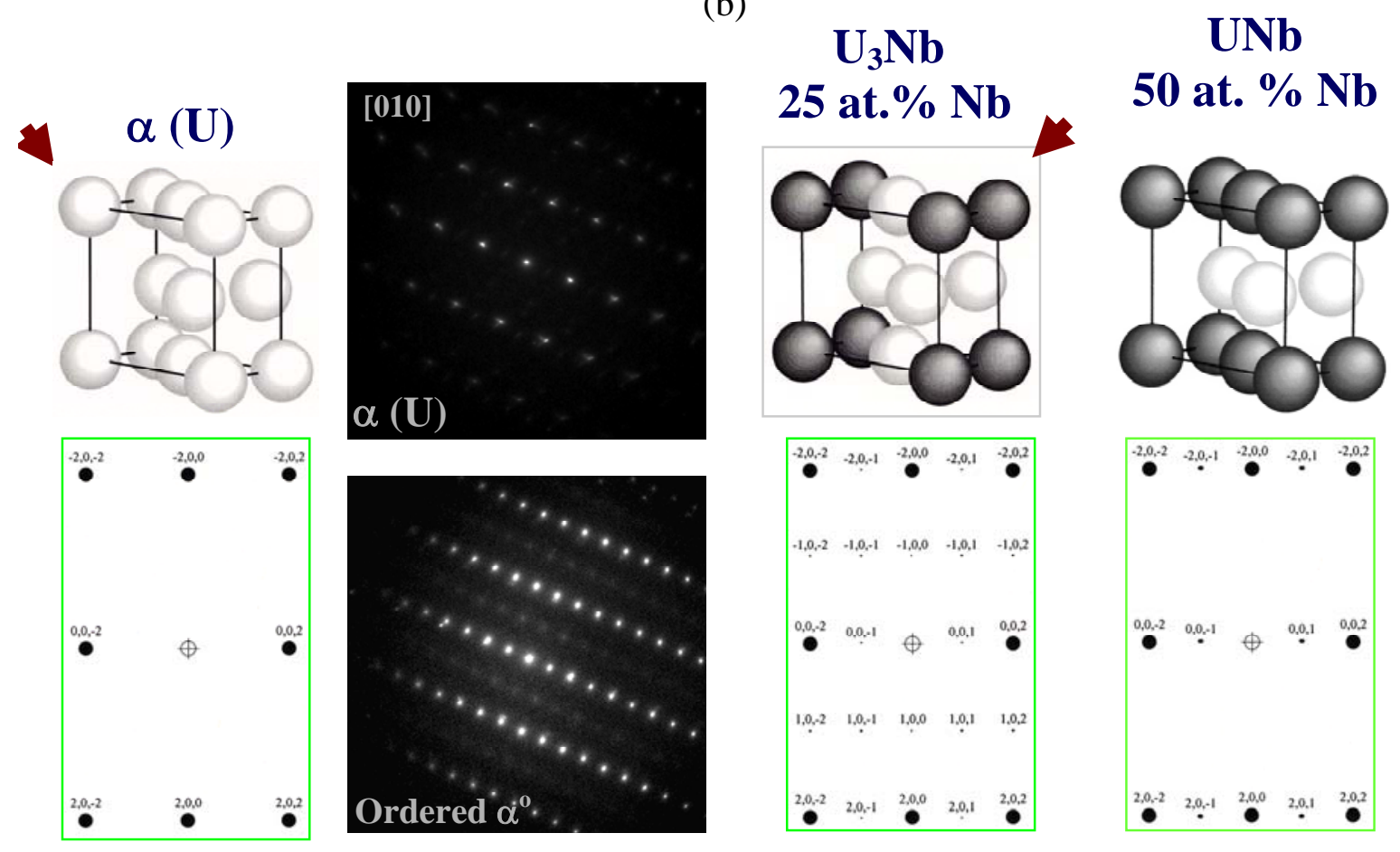

(c)

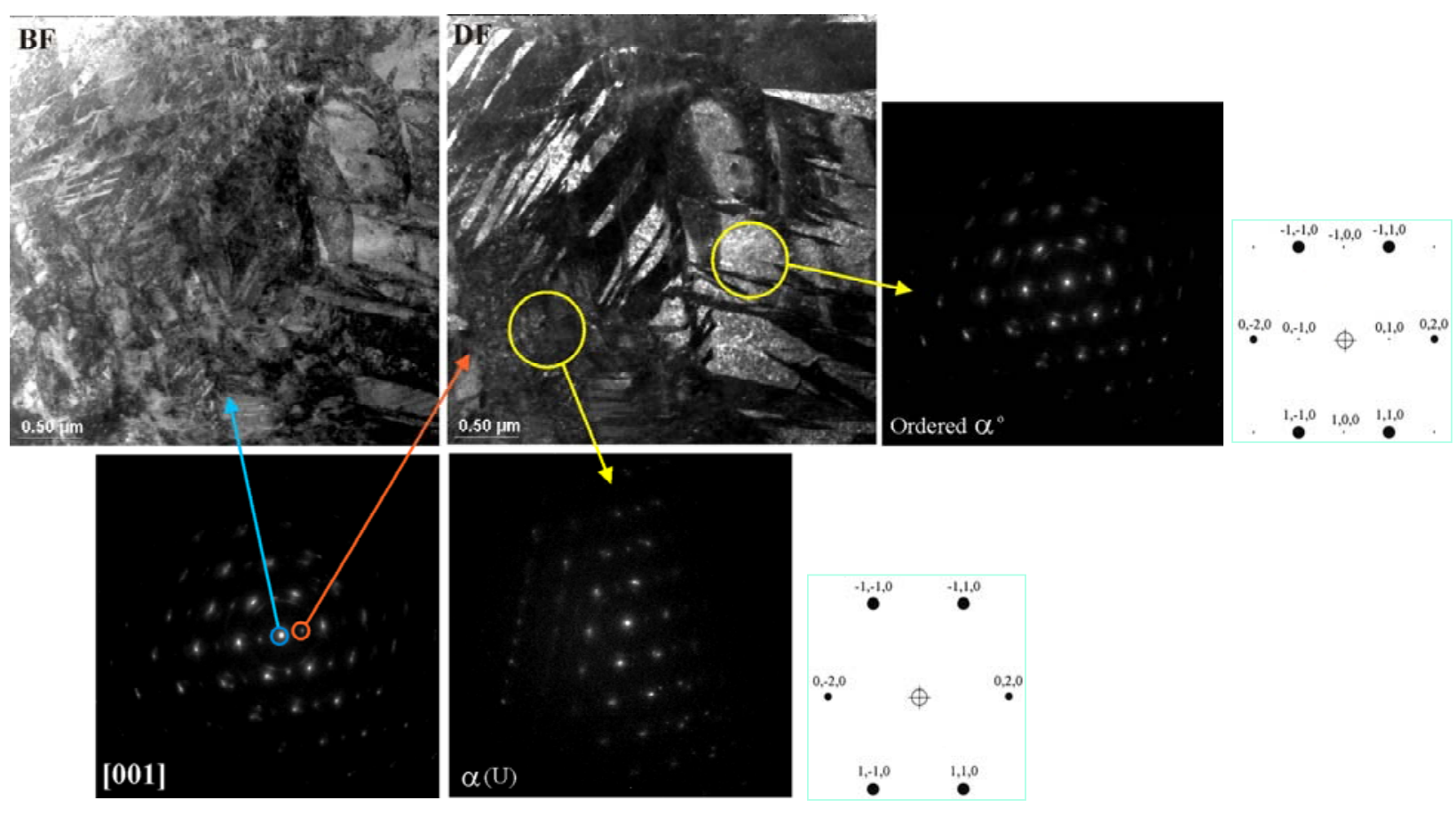


(d)

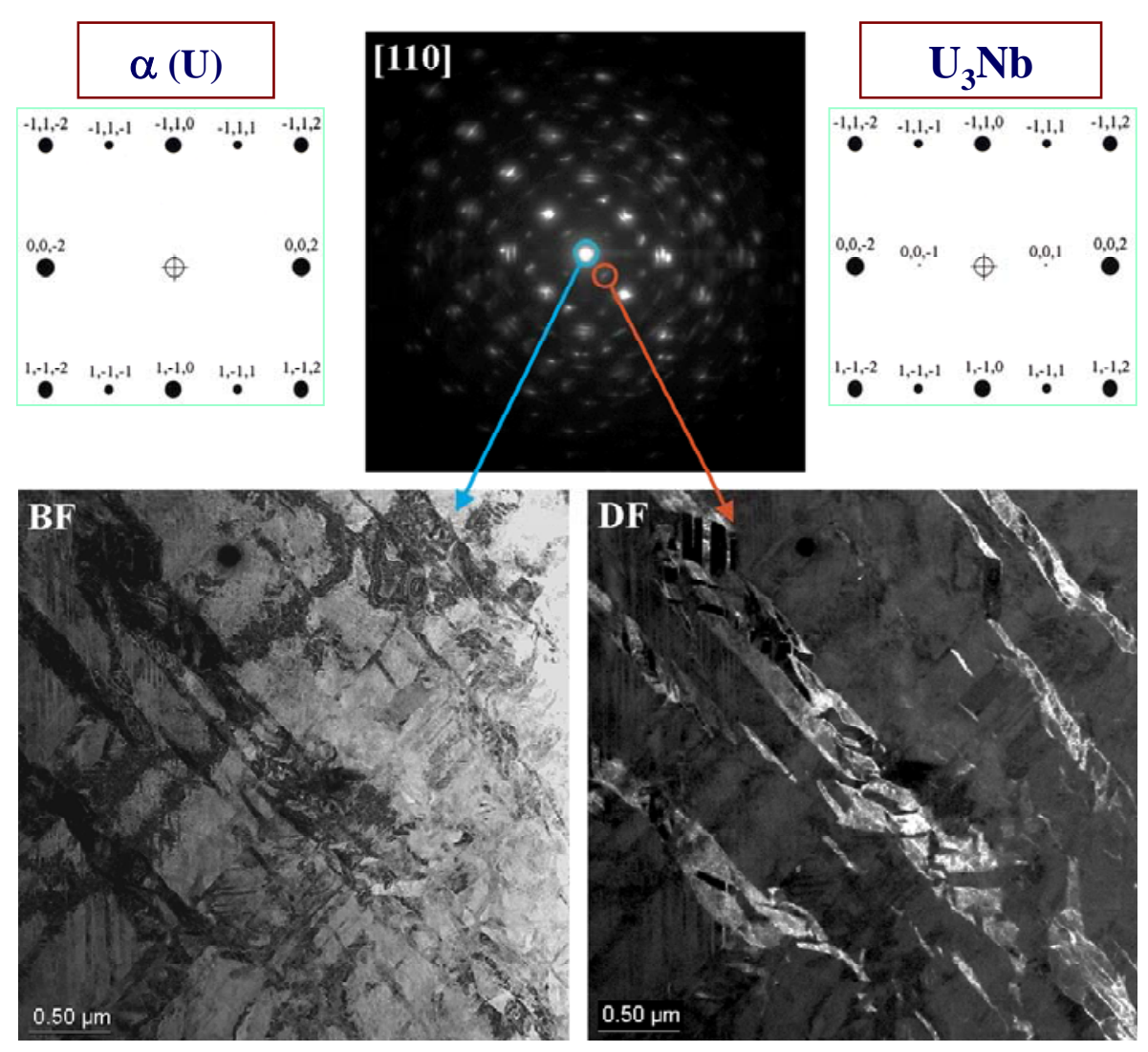

Figure 9: The identification of $\mathrm{Nb}$-depleted $\alpha$ phase and $\mathrm{Nb}$-enriched $\mathrm{U}_{3} \mathrm{Nb}$ ordered phase formed during accelerative aging of NA alloy at $200^{\circ} \mathrm{C}$ for 96 hours. The TEM images and diffraction patterns view from (a, b) [010]-zone, (c) [010]-zone, and (d) [110]-zone.

\section{Discussion}

In this study, we found that phase instability and chemical ordering occurred in WQ-U6Nb that have been in service for 15 years. This is equivalent to a natural aging of WQ-U6Nb for 15 years at ambient temperatures. The natural aging of the alloy results in the formation of antiphase domain boundaries (APBs) that appear as swirl-shaped features in TEM images (Figure 6). A further crystallographic simulation framework shows that the ordered phase domain resulted from the chemical ordering also contains a modulated structure along the [001] direction. The modulation wavelength is in the order of atomic size, i.e. $\lambda \approx 0.5 \mathrm{~nm}$, which is a distance between two (001) planes (Figure 7b). The formation of such an atomic scale modulation can be attributed to the aging at ambient temperatures as a result of low thermal energy, which makes atoms difficult to migrate over a long distance. Instead, the atoms can exchange their positions more effectively with their neighboring atoms. When the same species of atoms move to the same atomic planes, an atomic-scale modulated structure forms. In addition, the supersaturated parent phase becomes chemically ordered. Such modulation and chemical ordering help to reduce the free energy of the supersaturated solid solution. At elevated temperatures $\left(200^{\circ} \mathrm{C}\right)$, higher thermal energy enables atoms to diffuse over relatively longer distances, which leads to the formation of modulated structures with a longer wavelength $(\sim 3 \mathrm{~nm})$. Compared to the atomic-layered modulation structure formed at ambient temperature, the modulation structure with longer wavelength has fewer interfaces, but similar elastic energy. Thus, the long wavelength modulation is an energy-favored modulation structure. 
These two types of modulated structures formed at different temperatures are illustrated in Figure 10. These observations suggest that the supersaturated solid solution in WQ-U6Nb alloy is likely to be decomposed into modulated structure, in which a similar type of atomic aggregates is formed along the [001] direction. However, the wavelength of modulation is dependent on the aging temperatures. It is known from the TEM analysis of phase instability in water-quenched U6wt\% (14 at\%) $\mathrm{Nb}$ alloy under artificial and natural aging conditions that both spinodal decomposition and order-disorder transformation take place when the alloy is isothermally aged below $200^{\circ} \mathrm{C}$. The phase transformation sequence that occurs during isothermal aging below $200^{\circ} \mathrm{C}$ is quite similar but the wavelength $(\lambda)$ of spinodal decomposition and transformation rate are dependent upon aging temperatures. For aging at $200^{\circ} \mathrm{C}$ (artificial aging), the transformation rate is fast and $\lambda \approx 3 \mathrm{~nm}$ (Fig. 10); the transformation sequence is proposed to be supersaturated solid solution $\alpha^{\prime \prime} \rightarrow$ spinodal decomposition $\rightarrow \alpha_{1}$ (Nblean) $+\alpha_{2}$ (Nb-rich) $\rightarrow$ ordering transformation and precipitation $\rightarrow \alpha(\mathrm{U})+\alpha_{0}\left(\mathrm{U}_{3} \mathrm{Nb}\right)$. For aging at ambient temperatures (natural aging), the transformation rate is sluggish, and the wavelength of spinodal decomposition is reduced, i.e. $\lambda \approx 0.5 \mathrm{~nm}$ (Fig. 10); the transformation sequence is proposed to be supersaturated solid solution $\alpha^{\prime \prime} \rightarrow$ spinodal and ordering transformation $\rightarrow \alpha_{\text {po }}$ (partially ordered) $\rightarrow$ ordering transformation and precipitation $\rightarrow \alpha(U)+$ $\alpha_{0}\left(\mathrm{U}_{3} \mathrm{Nb}\right)$ as illustrated in Fig. 11. It can be clear seen in Fig. 12 that precipitation hardening accompanied with ductility embrittlement are resulted from the precipitation of $\mathrm{U}_{3} \mathrm{Nb}$ phase in the alloy, and the ductility of the alloy is reduced from $30 \%$ to $15 \%$ when the volume fraction of $\mathrm{U}_{3} \mathrm{Nb}$ increases to a volume fraction of $\sim 50 \%$.

\section{Supersaturated solid solution}

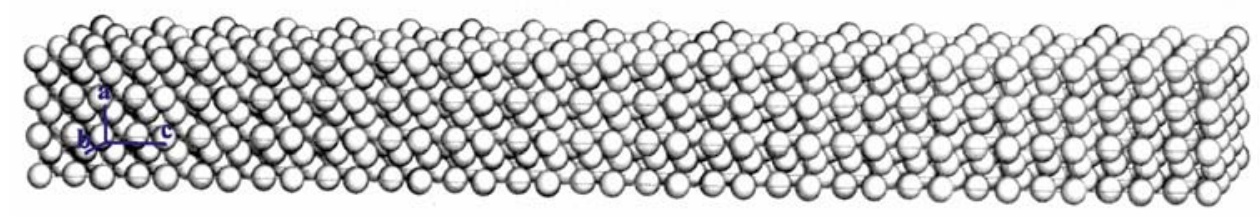

\section{Ordering at room temperature}

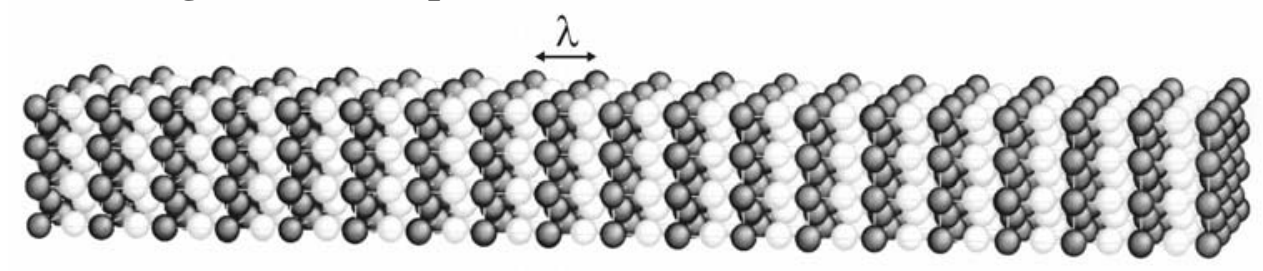

\section{Spinodal decomposition at $200^{\circ} \mathrm{C}$}

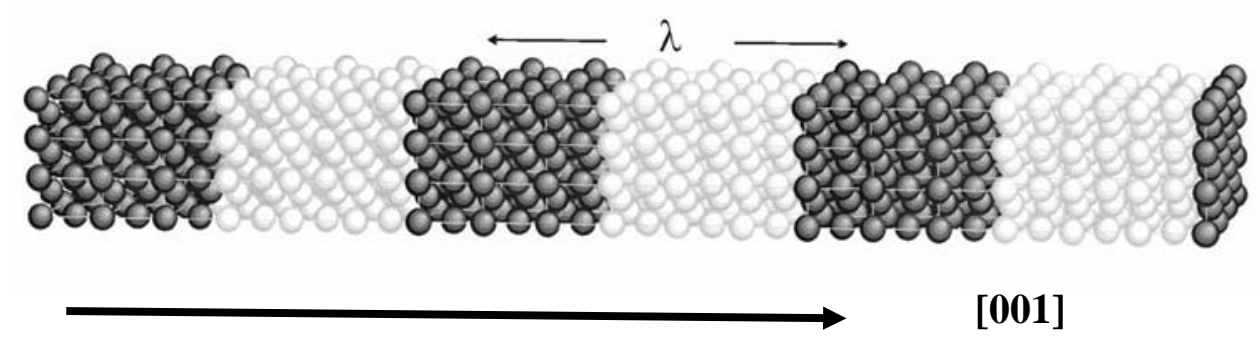

Figure 10: The wavelengths of the composition modulation are dependent on the aging temperatures. 


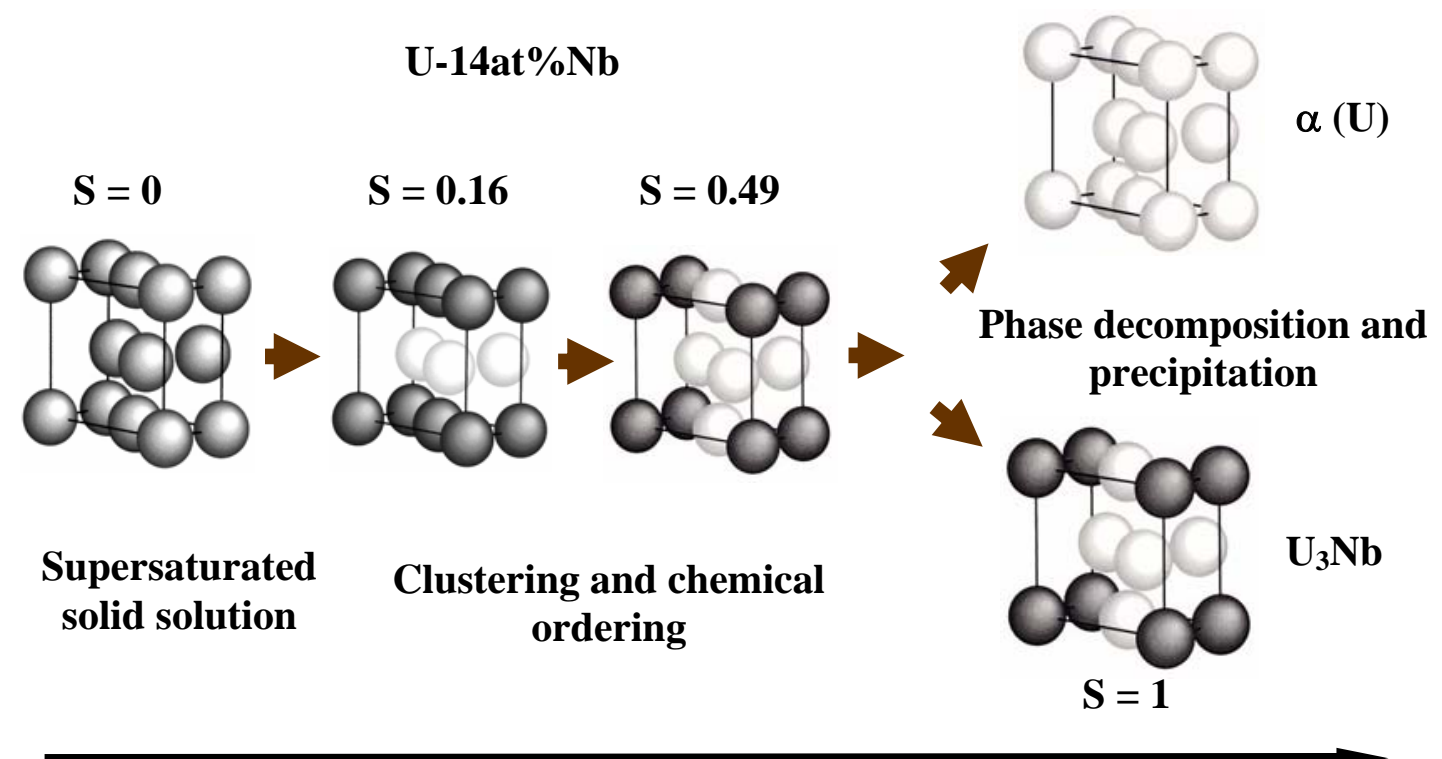

Aging time

Figure 11: Phase transformation paths that are affected by aging schedules.

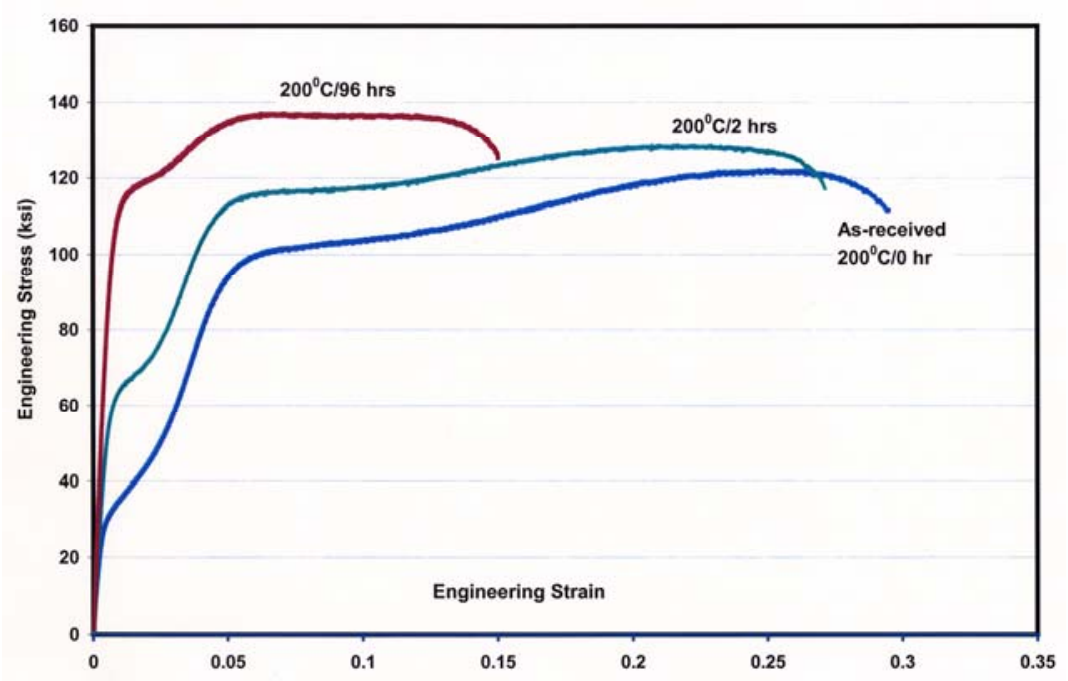

Figure 12: The changes of stress-strain response of NA alloy after accelerative aging for 2 hours and 96 hours, respectively, at $200^{\circ} \mathrm{C}$.

Figure 2 reveals that the WO-U6Nb alloy exhibits different aging strengthening and softening phenomena depending upon the different phase-transition pathways. For the WQ alloy subjected to artificial aging at $200^{\circ} \mathrm{C}$ without natural aging (NA), softening was rapidly observed within 16 hour. On the contrary, the NA alloy was continuously age-strengthened over an aging period of 96 hours at $200^{\circ} \mathrm{C}$. The stress-strain behavior change during the accelerative aging was studied using tensile testing. The results are shown in Figure 12. These stress-strain plots suggest that aging strengthening is at the expense of ductility. However, it is not known how the mechanical behavior of the alloy will be continuously changed over a period longer than 96 hours in aging. It is clear that future studies are required to study the phase transformation sequence over a longer period (after 96 hours). We also need to understand how the mechanical properties will be changed over a longer term of accelerative aging. Furthermore, WQ-U6Nb alloy has been in service for more than 20 years, we need to know how the microstructure properties will be12 
changed over the next 20 years or more. All these are important because it is critical to evaluate the reliability of the structures that were built up using this alloy. It is, therefore, important to continue the study to predict the microstructural evolution and the change of mechanical properties of the NA alloy at ambient temperatures.

\section{Conclusions}

A systematic study has been carried out to investigate the aging mechanisms of the WQU6Nb alloy. The changes of mechanical behavior and microstructural evolution during different aging schedules have been investigated using microhardness testing, tensile testing, and analytical TEM analysis methods. The salient conclusions are summarized as follows.

1. A composition modulation in atomic-scale occurred as a result of phase instability during long-term (15 years) natural aging process. This did not induce measurable change in microhardness.

2. During accelerative aging carried out on the NA alloy, the Nb-depleted $\alpha$ phase and $\mathrm{U}_{3} \mathrm{Nb}$ ordered phase were formed, leading to continuous hardening over an aging duration of 96 hours. The hardened alloy lost one half of its ductility by this time.

3. Spinodal decomposition occurred during artificial aging at the same temperature $\left(200{ }^{\circ} \mathrm{C}\right)$. The composition modulation formed during spinodal decomposition is $\sim 3 \mathrm{~nm}$ wavelength. Such modulation strengthened the alloy within the first 8 hours of aging, but caused weakening when the modulation started coarsening.

4. The aging behavior of the WQ-U6Nb alloy has been changed by the long-term service at ambient temperature. This suggests that future studies are required to explore the aging behavior at temperatures close to ambient temperatures.

\section{Acknowledgements}

This work was performed under the auspices of the U. S. Department of Energy by the University of California, Lawrence Livermore National Laboratory under Contract No. W-7405Eng-48. The authors gratefully acknowledge Bob McKoon, Anne Sunwoo, and T. C. Sun for their contribution to the artificial aging of U6Nb alloy, Vicki Mason-Reed for the microhardness measurement, and Rick Gross and Jessee Welch for the preparation of TEM foils.

\section{References:}

1. J. Koike, M.E. Kassner, R.E. Tate, and R.S. Rosen: The Nb-U (niobium-uranium) system Journal of Phase Equilibrium 19, 253 (1998).

2. R.A. Vandermeer: Phase transformations in a uranium + 14 at._\% niobium alloy. Acta Metallurgica 28, 383 (1980).

3. G. Beverini and D.V. Edmonds: An APFIM study of the aging behavior of U-6 wt-percent Nb. Journal De Physique 50, C8429 (1989).

4. K.H. Eckelmeyer, A.D. Romig, and L.J. Weirick: The effects of quench rate on the microstructure, mechanical properties, and corrosion behavior of U-6 WT PCT Nb. Metallurgical Transactions A- Physical Metallurgy and Materials Science 15, 1319 (1984).

5. D. Kelly, J.A. Lillard, W.L. Manner, R. Hanrahan, and M.T. Paffett: Surface characterization of oxidative corrosion of U-Nb alloys. Journal of Vaccum Science \& Technology A-Vaccum Surfaces and Films 19, 1959 (2001).

6. R.A. Vandermeer, J.C. Ogle, and W.G. Northcutt: A phenomenological study of the shape memory effect in polycrystal uranium niobium alloys. Metallurgical Transactions A-13 
Physical Metallurgy and Materials Science 12, 733 (1981).

7. R.D. Field, D.W. Brown and D.J. Thomas: Texture development and deformation mechanisms during uniaxial straining of U-Nb shape-memory alloys. Philosophical Magazine 85, 1441 (2005).

8. R.J. Jackson and D.V. Miley: Tensile properties of Gamma quenched and aged uramiumbased niobium alloys. ASM Transactions 61, 336 (1968).

9. K. Orlov, V.M. Teplinskaya, and N.T. Chebotarev: Decomposition of a metastable solid solution in uranium-molybdenum alloy. Atomic Energy 88, 42 (2000).

10. J.C. Zhao and M.R. Notis: Ordering transformation and spinodal decomposition in Au-Ni alloys. Metallurgical and Materials Transactions, 30A, 707 (1999).

11. J.W. Cahn: Transaction of TMS and AIME 242, 166 (1968).

12. J.W. Edington: Practical Electron Microscopy in Materials Science, Van Nostrand Reinhold, New York, 1976. 